\title{
(DES)VALORIZAÇÃO DA ENFERMAGEM: IMPLICAÇÕES NO COTIDIANO DO ENFERMEIRO
}

\author{
Candice Ellen Barbalho Lage ${ }^{1}$, Marcelo da Silva Alves ${ }^{2}$
}

Objetivo: compreender as percepções dos enfermeiros da Atenção Primária à Saúde de Juiz de Fora - MG acerca do reconhecimento e valorização da sua profissão e suas implicações no seu cotidiano. Metodologia: pesquisa qualitativa do tipo descritiva, realizada com enfermeiros atuantes nas Unidades de Atenção Primária à Saúde (UAPS) da cidade de Juiz de ForaMG, no periodo de outubro a dezembro de 2014, a partir de entrevistas semiestruturadas, consideradas por meio da análise de conteúdo. Resultados: foram organizados em quatro categorias, intituladas Valorização profissional x empenho profissional, Valorização profissional x fator motivacional, (Des)valorização profissional x (des)encantamento profissional e Valorização profissional x entusiasmo profissional, as quais revelam de que forma a (des)valorização da enfermagem se reflete no cotidiano do enfermeiro. Conclusão: concluiu-se que na realização do cuidado de enfermagem oferecido aparecem os reflexos de um trabalho frustrado ou excelente, todavia, cabe ao profissional permitir se afetar, ou não, motivar-se, ou não.

Descritores: Enfermagem, Motivação, Valorização social.

\section{EVALUATION OF NURSING AND IMPLICATIONS IN NURSES' DAYLY ROUTINE}

Objective: to understand the perceptions of nurses working in Primary Health Care of Juiz de Fora-MG about the recognition and appreciation of their occupation and its implications in their everyday lifes. Methodology: descriptive qualitative research methodology was used, performed with nurses working in Primary Health Care of Juiz de Fora-MG, from October to December 2014, from a semi-structured interview., examined bycontent analysis. Results: they were organized in four categories, entitled professional valuation $x$ professional effort, professional valuation x motivational factor, professional (un)valuation $x$ professional (dis)enchantment and professional value x professional enthusiasm, which reveal how the (un)importance of nursing reflected in nurses' daily lives. Conclusion: It concludes that in carrying out the nursing care offered appear the reflections of a frustrated or excellent job.

t was concluded that the realization of the offered nursing care appear the reflexes of a frustrated or excellent job; however, it is up to professional allow to affect, or not, to motivate yourself, or not.

Descriptors: Nursing; Motivation; Social desirability.

\section{LA DEVALUACIÓN DE LA ENFERMERÍA Y LAS IMPLICACIONES PARA EL USO DIARIO DE LAS ENFERMERAS}

Objetivo: comprender la percepción de enfermeras de Atención Primaria de Salud de Juiz de Fora - MG, sobre el reconocimiento y la valoración de su profesión y sus implicaciones en su vida diaria. Metodología: investigación cualitativa descriptiva, hecha con enfermeras de Atención Primaria de Salud de Juiz de Fora - MG, de octubre a diciembre 2014. Los datos se obtuvieron a partir de entrevistas semiestructuradas y fueron analizados mediante el análisis de contenido. Resultados: fueron organizados en cuatro categorías, titulado como valorizacion profesional $x$ desarrollo profesional, valorizacion profesional $x$ factor de motivación, (des)valorizacion profesional x (des)encanto profesional y valorizacion profesional x entusiasmo profesional, que revelan cómo la (des) valorización de la enfermería se refleja en la vida cotidiana de las enfermeras. Conclusión: se concluye que la realización de los cuidados de enfermería han proporcionado mostrar los reflejos de un trabajo frustrado o excelente; sin embargo, es la responsabilidad profesional permitirse afectar, o no, de motivarse, o no.

Descriptores: Enfermería; Motivación; Deseabilidad social.

${ }^{1}$ Enfermeira. Mestre em Enfermagem. E-mail: candicelage@hotmail.com

2Enfermeiro.Doutor em Saúde Coletiva.Professor Associado da Faculdade de Enfermagem da Universidade Federal de Juiz de Fora, Juiz de Fora. 


\section{INTRODUÇÃO}

A enfermagem é permeada por imagens estereotipadas e primitivas, percepções errôneas que derivam da história da profissão e que se perpetuam até os dias de hoje $\mathrm{e}^{(1)}$.

O estudo da história da enfermagem leva a compreender que as lutas travadas contra os preconceitos presentes no imaginário coletivo tem importância na aceitação e no reconhecimento social dessa profissão. A falta de reconhecimento não é discutida com a devida importância, ocupando posição secundária nos debates sobre gestão, embora seu estudo seja essencial para a cooperação e para a subsequente produtividade ${ }^{(2.3)}$

A importância desse reconhecimento encontra-se, entre outros, na influência que a valorização da profissão, em suas variadas dimensões, tem no desempenho profissional. Implicações negativas geradas pela pouca visibilidade da enfermagem estão relacionadas à insatisfação e ausência de motivação no contexto de trabalho(4). A falta de visibilidade e reconhecimento da profissão pela equipe de saúde e pelos pacientes pode comprometer a construção de vínculos, como também a efetivação do cuidado(4).

O reconhecimento da enfermagem e o prestígio social podem fazer com que o enfermeiro se sinta pleno, com as atividades desempenhadas no contexto de trabalho e perante a sociedade. O trabalhador, quando reconhecido, desenvolve o seu fazer com maior comprometimento e satisfação, o que pode motivar o enfermeiro a desenvolver a assistência ao paciente com maior qualidade por sentir-se valorizado ${ }^{(4.5)}$.

\section{Objetivo}

Este estudo teve como objetivo compreender as percepções dos enfermeiros da Atenção Primária à Saúde de Juiz de Fora - MG acerca do reconhecimento e valorização da sua profissão e suas implicações no seu cotidiano.

\section{METODOLOGIA}

Trata-se de um estudo qualitativo do tipo descritivo, realizado com 12 enfermeiros atuantes nas Unidades de Atenção Primária à Saúde (UAPS) da cidade de Juiz de Fora-MG.

A Atenção Primária à Saúde em Juiz de Fora é composta por 67 unidades, sendo 48 na área urbana e 19 na zona rural. Para a seleção dos participantes, foram utilizados, como critérios de inclusão, os enfermeiros do cenário acima descrito, que trabalhassem em unidades da área urbana e que aceitassem participar, demonstrando sua aquiescência por meio da assinatura do Termo de Consentimento Livre e Esclarecido. Foram utilizados, como critérios de exclusão, os enfermeiros residentes e os enfermeiros que estivessem em período de férias, licenças, ou que não fossem localizados durante o período da coleta de dados. As unidades que integram este estudo foram escolhidas de forma aleatória, a partir de uma lista com todas as unidades urbanas existentes.

A coleta de dados foi realizada, no período de outubro a dezembro de 2014, nas próprias UAPS, em dias e horários escolhidos pelos próprios participantes, agendadas de acordo com sua disponibilidade, utilizando-se a técnica da entrevista semiestruturada como instrumento. As entrevistas abordaram pontos tais como: de que modo o enfermeiro se percebe representado pelos pacientes e pela sociedade em geral, como essa representação interfere no seu dia a dia, fatores de (in)satisfação no trabalho e o que representa para ele ser enfermeiro. As entrevistas foram gravadas em mídia digital, para que se obtivesse total fidedignidade aos relatos. O número de entrevistas não foi estabelecido a priori, uma vez que foi seguido o critério de saturação.

Após a coleta de dados, as entrevistas foram transcritas na íntegra, de forma atenta e minuciosa e foi realizada uma leitura recorrente das mesmas para organização do material, seguida de exploração exaustiva, para assim identificar as unidades estruturais significantes. Em seguida, os dados foram agrupados em categorias analíticas a partir dos sentidos e dos significados das falas dos sujeitos e analisadas a partir da análise de conteúdo, que é: "um conjunto de técnicas de análise das comunicações visando a obter, por procedimentos sistemáticos e objetivos de descrição do conteúdo das mensagens, indicadores (quantitativos ou não) que permitam a inferência de conhecimentos relativos às condições de produção/recepção (variáveis inferidas) destas mensagens" (7:48)).

Com a finalidade de preservar a identificação e garantir o sigilo, os participantes foram denominados por "ENF", seguidos do número correspondente à ordem em que foram entrevistados.

Todas as fases de realização da pesquisa contemplaram a Resolução do CNS n. 466(6), de 12 de dezembro de 2012 e a mesma foi aprovada pelo Comitê de Ética em Pesquisa da Universidade Federal de Juiz de Fora (CEP/UFJF), sob o parecer 622.548 de 22/04/2014 e CAAE no 27622014.0.0000.5147.

\section{RESULTADOS}

Em relação ao perfil, a idade dos 12 participantes variou entre 29 e 57 anos; o tempo de formados, entre quatro anos e meio e 32 anos; tempo de atuação na unidade de saúde em que trabalha, entre um mês e nove anos; em relação às titulações máximas, nove possuem especialização e três possuem mestrado. Todos são concursados na prefeitura do municipio.

A partir da análise dos dados, emergiram quatro categorias, que são apresentadas logo a seguir:

\section{1) Valorização profissional $x$ empenho profissional}

A valorização e o reconhecimento do trabalho do 
enfermeiro estão aquém da expectativa e importância atribuída pelo mesmo e a ausência desses componentes assume um caráter negativo na motivação e desempenho do seu trabalho: Interfere, interfere negativamente. Vira um ciclo vicioso, né? A partir do momento que eu não tenho uma valorização, eu não faço o meu trabalho da melhor forma que eu poderia fazer. Eu faço o que é obrigação, e acabou, eu nunca vou além, mesmo tendo esse potencial de ir além. [...] não que o que eu faça ou que outras pessoas façam não seja adequado, a gente faz, cumpre as nossas obrigações e só. (ENF 10). Eu acho assim, no meu dia a dia eu acho que não interfere tanto não, mas eu acho que pra muitas pessoas sim, porque elas acabam deixando de lado, deixam correr solto do jeito que dá, porque às vezes você não tem uma valorização [...]. (ENF 11).

\section{2) Valorização profissional $x$ fator motivacional}

As percepções que os enfermeiros entrevistados têm de si e dos papéis que desempenham na sociedade são afetados por alguns aspectos referentes à valorização obtida: [...] eu já até pareiprapensar, sehoje, agente quer melhorar, a prevenção, fazer o citopatológico, fazer acompanhamento do prénatal, mas às vezes parece até que é uma mão de obra barata, que tem o médico na equipe, mas assim, utiliza-se da nossa mão-de-obra, pra dar conta de todos esses problemas. Eu sinto uma desualorização e assim, desmotiva, né? (ENF 11).

Por outro lado, a motivação é originada a partir das necessidades internas e de fatores de satisfação intrínsecos aos indivíduos e não de situações extrínsecas ao mesmo ${ }^{(8)}$, como visto na fala a seguir: Olha, eu não me vejo fazendo outra coisa [risos]. [...] o fato de eu estar presente, de eu poder ajudar de alguma forma, de eu ter um conhecimento maior a respeito de determinada coisa e orientar esse paciente, e você ver realmente que ele atingiu alguma meta, algum objetivo, ou teve uma mudança de vida, ou teve um restabelecimento da saúde, eu acho que isso é que me faz levantar todo dia, entendeu? Para poder vir trabalhar, apesar de realmente não ser reconhecida. (ENF 10).

\section{3) (Des)valorização profissional x (des)encantamento profissional}

A representação da imagem do enfermeiro e o cenário atual em que a profissão se encontra têm implicações profundas nos seus exercentes, que passam a questionar se é válido permanecer nessa profissão: Ah já, já pensei sim [em mudar de profissão], porque vai envolvendo essa sobrecarga de trabalho, essa falta de reconhecimento, muitas vezes da profissão perante a mídia, perante a outras pessoas, igual a minha familia e os meus amigos sabem, vizinhos próximos, mas no geral às vezes você fica um pouco frustrado assim, que dia que vou ser reconhecida? Cabe muito a você também, você mostrar o seu trabalho, se dedicar, tem essa questão também da pessoa, mas a construção cultural, então já pensei em mudar de profissão sim. E aí acaba que é por esse motivo assim, dessa visão meio assim, do inferior, né, você é visto como inferior ali. (ENF 6). Sim, o que acontece, quando você percebe que as coisas não se encaminham, então sem dúvida você tem essa vontade [de mudar de profissão]. (ENF7).

4) Valorização profissional $x$ entusiasmo profissional

Apresentando a mesma visão, porém por outra ótica, surgem os depoimentos que mostram como a presença do reconhecimento e da valorização laboral podem ter repercussões positivas na vida do trabalhador: A forma que a pessoa reconheceu o que você fez, que você tentou ajudar. Isso te motiva a ajudar outras pessoas, e a gente faz isso direto, até sem ver. (ENF 2). Essa importância que as pessoas dão ao meu trabalho? Ah, isso é gratificante, né? A pessoa chegar e dizer pra você "eu vim aqui agradecer por isso, por aquilo", às vezes uma coisa mínima que a gente faz, isso é gratificante, isso é bom, pra te ajudar no seu dia a dia, né, poxa, vou continuar nesse trabalho porque realmente, eu tô fazendo aquilo que eu gosto e as pessoas estão reconhecendo. (ENF 3).

Para outros enfermeiros, a presença ou ausência do reconhecimento do usuário é indiferente, uma vez que eles vão à unidade para realizar o seu serviço independente do valor que outras pessoas atribuem à sua atuação: Não, eu faço tudo que eu deveria fazer, eu sigo protocolos do Ministério, manuais do Ministério e a minha consciência, então agradando ou não agradando eu vou fazer o que tem que ser feito [...]. (ENF 9). Eu venho, faço o meu serviço, gosto de fazer o meu serviço bem feito, porque eu vou pra casa, 
gosto de ficar com a consciência tranquila, porque eu gosto, eu vejo resultado no que eu faço, mas eu não importo com satisfação não. É claro que elogio é sempre bom, mas nem sempre a gente consegue agradar todo mundo também, né [...]. (ENF 9).

\section{DISCUSSÃO}

Observou-se, neste estudo, que a falta de valorização e reconhecimento do trabalho do enfermeiro pode interferir diretamente no seu empenho, na sua autoestima e, consequentemente, na relação do profissional com o seu trabalho e consigo mesmo, uma vez que os entrevistados relatam que, ao não se sentirem valorizados, os trabalhadores deixam de se empenhar no exercício da sua função.

O fazer profissional do enfermeiro é mobilizado e estimulado por meio do reconhecimento do seu trabalho. A satisfação no trabalho e o sentimento de realização profissional são ingredientes

que contribuem para o desenvolvimento do seu fazer e impulsionam a sua busca por crescimento profissional(9). Logo, na realização do cuidado de enfermagem oferecido, aparecem os reflexos de um trabalho frustrado ou excelente $^{(10)}$.

Nesse sentido, nota-se, nas falas, que por não se sentir valorizado e reconhecido pelo trabalho que exerce, o enfermeiro perde o estímulo para utilizar o seu potencial máximo na sua execução. Nesse contexto, podem ficar prejudicados o próprio profissional, que não se sente feliz, nem se realiza no seu trabalho, e o usuário, que tende a encontrar um profissional desmotivado em atendê-lo, ou que realiza sua assistência de maneira automática, sem refletir sobre o seu papel, interferindo, assim, na qualidade do serviço prestado.

Quando se soma a esse contexto um atendimento de baixa qualidade, em que o profissional não demonstra entusiasmo ou empenho para atender às necessidades do cliente, voltase ao ponto em que o cliente não irá valorizar o profissional nem o seu ofício, entrando assim em um ciclo em que um fator sempre afeta e é afetado pelo outro.

Nessa linha de raciocínio, outros autores ${ }^{(9,1)}$ narram que a valorização profissional apresenta-se densamente conectada à motivação, sendo determinante na expressão da subjetividade e no comportamento no trabalho. Assim, do mesmo modo que a desmotivação laboral é passível de determinar a desestruturação no desenvolvimento do trabalho da enfermagem, o caminho contrário é reciproco, tornando-se assim um esquema cíclico de retroalimentação.

Além disso, os enfermeiros, muitas vezes ofuscados, anseiam o reconhecimento do seu fazer e sofrem quando se empenham para qualificar seu trabalho e não são bem avaliados e valorizados ${ }^{(12)}$. É possível perceber esse sofrimento em alguns relatos das entrevistas, observando-se que a desvalorização sentida pelos enfermeiros parece afetar a forma como eles se percebem, fazendo com que os próprios profissionais questionem sua importância e seu valor para a sociedade, e se eles existem. Fica claro que essa falta de valor, atribuida à profissão, os desmotiva.

Todavia, apesar dos entrevistados relatarem a vontade de muitas vezes buscarem outros caminhos profissionais, todos disseram que só assumiriam esse novo rumo após sua aposentadoria, pois, apesar de muitas insatisfações na área, exercem a profissão por amor e afinidade. Nesse sentido, os autores, Cardozo et al. ${ }^{(13)}$ dizem que "a Enfermagem é uma profissão que recruta seus executores, e que, mesmo insatisfeitos, humilhados e desvalorizados, buscam prestar uma atenção diferenciada para quem necessitar", e que mesmo imersos em dificuldades cotidianas de trabalho, os enfermeiros continuam a exercer um cuidado de qualidade com um sorriso no rosto.

Possivelmente, esse conformismo está ainda associado à sua carga histórica, aos sentimentos e comportamentos valorizados e norteados pelo apostolado e pela submissão. Assumindo uma competência pouco valorizada, o profissional preza pelo bom relacionamento e segue cumprindo seu papel de assistir o usuário na unidade. Esses fatos parecem inibir o enfermeiro a ousar derrubar barreiras para mostrar seu próprio valor, o que pode contribuir para que a profissão e o profissional não conquistem o devido respeito e continuem socialmente invisiveis.

Alguns autores ${ }^{(4)}$ expressam que a dificuldade do enfermeiro em mudar a visão de sua imagem está associada a fatores variados e, entre eles, destaca-se o rompimento do elo com o silêncio para passar a destacar suas próprias qualidades. Esse fator o impede de conseguir mostrar suas 
próprias virtudes, o que contribui para que socialmente a profissão e o profissional continuem cada vez menos visiveis.

O profissional de enfermagem, ao perceber-se como ser humano e profissional invisivel, sente-se desvalorizado por ser assim percebido pelo outro ser. Condições ambíguas se fazem presentes nas ações e atitudes de cuidado, principalmente por serem elas rotineiras, passando despercebidas pelo outro (situação invisível), entretanto, essa ausência é vista como um não-cuidado (situação visivel). Revelam-se, aí, os movimentos ambíguos, complexos, contraditórios e até divergentes, mas que fazem parte das relações humanas inseridas no cuidado e não cuidado ${ }^{(14)}$.

Por outro lado, analisando-se o mesmo contexto, porém, sob outra ótica, fica nítida a satisfação do enfermeiro quando the é dada a devida importância pelo seu trabalho. Os gestos dos usuários ao elogiá-los, presenteá-los ou simplesmente agradecê-los são vistos como um retorno positivo pela prestação de seus serviços, e assim eles se sentem reconhecidos, parceiros, com vínculos.

Apesar de alguns enfermeiros afirmarem que não se importam com o valor atribuido ao seu exercício, em outros momentos, os mesmos queixam-se da baixa valorização da profissão, e da necessidade de maior reconhecimento.

\section{CONCLUSÃO}

Compreendeu-se, a partir deste estudo, que para o exercício apropriado e satisfatório de uma determinada profissão são imprescindiveis a motivação e a valorização do profissional em seu ambiente de trabalho. Percebe-se que, do mesmo modo em que as frustrações e desalentos podem refletir-se de forma negativa no trabalho do enfermeiro, as percepções, valores e sentimentos positivos também se refletem no seu exercício profissional.

Desse modo, entende-se que a motivação no trabalho do enfermeiro sofre influência de diversos fatores e que em vários momentos sua frustração é justificável, porém, cabe ao profissional permitir-se afetar-se ou não, motivar-se ou não.

A mola propulsora que o conduz no campo da satisfação, tanto psicológica, emocional e profissional, está dentro do próprio Enfermeiro. Aprender a dar e receber amor são tarefas que começam consigo mesmo, partindo da decisão de por fim a todas as dificuldades e comportamentos de menos valia que porventura tenham se tornado seu estilo de vida. A sua autoimagem positiva reforça a aptidão, a valorização, o aprimoramento e o empenho para obter as realizações e metas planejadas. A motivação profissional se estabelece pelos graus de realização e satisfação nele encontrados.

\section{REFERÊNCIAS}

1. Oguisso T, Souza Campos PF Moreira A. Por que e para que estudar história da enfermagem? Enferm Foco. 2013:4(1):49-53.

2. Dejours C. Subjetividade, trabalho e ação. Rev Produção. 2004;14(3):2734.

3. Traesel ES, Merlo ÁRC. A psicodinâmica do reconhecimento no trabalho de enfermagem. Psico. 2009:40(1):102-9.

4. Avila LI, da Silveira RS, Lunardi VL, Machado GFF, Mancia JR, da Silveira JT. Implicações da visibilidade da enfermagem no exercicio profissional. Rev Gaúcha Enferm. 2013;34(3):102-9.

5. Silveira RS, Funck CR, Lunardi VL, Avila LI, Vidal DAS. Percepção dos trabalhadores de enfermagem acerca da satisfação no contexto do trabalho na UTI. Enferm Foco. 2012;3(2):93-6.

6. Brasil. Resolução, № 466 do Conselho Nacional de Saúde, de 12 de dezembro de 2012 (BR). Aprova as diretrizes e normas regulamentadoras de pesquisas envolvendo seres humanos Diário Oficial da União. 2012.

7. Bardin, L. Análise de conteúdo. São Paulo: Edições 70; 2011.

8. Braga Junior SS, Santos RR, Carvalho JS, Silva GdP, Silva Dd
Possibilidades entre Motivação e Produtividade: Um Estudo de Caso no Alto Tietê. Sociedade, Contabilidade e Gestão. 2013:8(3).

9. Sprandel LIS, Vaghetti HH. Valorização e motivação de enfermeiros na perspectiva da humanização do trabalho nos hospitais. Rev Eletr Enf. 2012:14(4):704-802.

10. Regis L, Porto IS. Necessidades humanas básicas dos profissionais de enfermagem: situações de (in) satisfação no trabalho. Rev Esc Enferm USP. 2011:45(2):334-41.

11. Dejours C. A Banalizacao Da Injustica Social. Rio de Janeiro: FGV Editora; 2000 .

12. Maissiat GdS, Lautert L, Dal Pai D, Tavares JP. Contexto de trabalho. prazer e sofrimento na atenção básica em saúde. Rev Gaúcha Enferm. 2015:36(2):42-49. 2015.

13. Cardozo EG, Silva DLdLCd, Guilherme FJdA, Ferreira RdS. A insatisfação profissional na enfermagem: Problemas Psicossociais. Revista Rede de Cuidados em Saúde. 2015:9(2).

14. Baggio MA, Erdmann AL. (In) visibilidade do cuidado e da profissão de enfermagem no espaço de relações. Acta Paul Enferm. 2010;23(6):745-50. 